\title{
Differential Expression of $\alpha$-Synuclein Splice Variants in the Brain of Alcohol Misusers: Influence of Genotype*
}

Paulina Janeczek ${ }^{1}$, Corinne Brooker ${ }^{1}$, Peter Dodd $^{2}$ and Joanne M. Lewohl ${ }^{1}$

${ }^{1}$ Menzies Health Institute Queensland, School of Medical Sciences, Griffith University, Gold Coast Campus, Southport, Australia

${ }^{2}$ School of Chemistry and Molecular Biosciences, University of Queensland, Brisbane, Australia Address correspondence to: Dr. J. M. Lewohl, School of Medical Science, Gold Coast Campus, Griffith University 4222, AUSTRALIA. tel +61-7-5552-7096; fax +61-7-5552-8908; email:

j.lewohl@griffith.edu.au

* Supplementary material can be found by accessing the online version of this paper at http://dx.doi.org and by entering doi:... 


\section{ABSTRACT}

Background: Chronic alcohol misuse causes damage in the central nervous system that may lead to tolerance, craving and dependence. These behavioural changes are likely the result of cellular adaptations that include changes in gene expression. $\alpha$-Synuclein is involved in the dopaminergic reward pathway, where it regulates dopamine synthesis and release. Previous studies have found that the gene for $\alpha$-synuclein, $S N C A$, is differentially expressed in alcohol misusers. Methods: The present study measured the expression of three $\alpha$-synuclein variants, SNCA-140, SNCA-112, and SNCA-115 in the prefrontal cortex of controls and alcohol misusers with and without cirrhosis of the liver. In addition, eight SNPs located in the 5'- and 3'-UTRs were genotyped in a Caucasian population of 125 controls and 115 alcohol misusers. Results: The expression of SNCA-140 and SNCA-112 was significantly lower in alcohol misusers with cirrhosis than in controls. However, SNCA-115 expression was significantly greater in alcohol misusers with cirrhosis than in controls. Allele and genotype frequencies differed significantly between alcohol misusers and controls for three SNPs, rs356221, rs356219 and rs2736995. Two SNPs, rs356221 and rs356219, were in high linkage disequilibrium. There was no increased risk of alcoholism associated with specific genotypes or haplotypes. Our results suggest that the rs356219/356221 G-A haplotype may decrease the chance of having an alcohol misuse phenotype. Conclusion: These findings suggest that alcohol misuse may alter the expression of the individual $\alpha$-synuclein splice variants differently in human brain. There was no evidence of an effect of sequence variation on the expression of $\alpha$ synuclein splice variants in this population.

KEYWORDS: haplotype; human; prefrontal cortex; SNCA, variants, 3'-UTR 


\section{INTRODUCTION}

Alcohol misuse results in a significant burden of disease in Australia and throughout the world. This is commonly attributed to the effects of alcohol on the brain and liver, resulting in brain damage and liver cirrhosis respectively (Crews et al., 2005). However, alcohol affects all organs of the body and is associated with an increased incidence of some types of cancers, greater susceptibility to inflammatory diseases, and difficulties with wound and bone healing (Miranda et al., 2010). The mechanism by which alcohol causes such diverse effects is not well understood.

In the brain, chronic alcohol misuse results in persistent changes in function that are manifested as tolerance, physical dependence, craving, and other behavioural changes (Nestler and Aghajanian, 1997). The changes in brain function originate from alterations in gene expression that, in turn, underlie the cellular adaption to chronic alcohol misuse (Anni and Israel, 2002; Nestler, 2000). We and others have used whole-genome microarrays to delineate genes with altered expression in the brain following long-term alcohol consumption (Lewohl et al., 2000; Liu et al., 2004, 2006; Mayfield et al., 2002), as well as the potentially confounding effects of concomitant diseases such as liver cirrhosis (Liu et al., 2007). The studies have identified genes that likely underlie the adaptive response of neurons in the prefrontal cortex, a brain region that is particularly susceptible to long-term alcohol misuse. These include genes involved in protein trafficking, myelination, ubiquitination, apoptosis, cell adhesion, neurogenesis, and neural disease. Studies using whole-genome microarrays (Lewohl et al., 2000; Liu et al., 2004, 2007, 2006; Mayfield et al., 2002) and 2-D gel proteomics (Etheridge et al., 2009; Lewohl et al., 2004) have suggested that $\alpha$ synuclein is differentially regulated in the brain of alcohol misusers relative to controls. A recent study analysing data available from GWAS, animal and human genetic and gene expression studies found the $\alpha$-synuclein gene (SNCA) to be the top candidate gene for alcoholism (Levey et al., 2014).

$\alpha$-Synuclein mRNA exists in at least four distinct splice variants that produce functional polypeptides. These variants vary in their coding sequence as well as in the lengths of their 3'untranslated regions (3'-UTRs). The variants include the full-length (wild type) sequence comprised of 6 exons that encodes a 140 amino acid protein. Three shorter exon skipping variants include the 126 amino acid variant, a transcript missing exon 3; the 112 amino acid variant, which is missing exon 5; and the 98 amino acid variant, where both exons 3 and 5 are absent. Although little is 
known about the function of the polypeptides that arise from these individual splice variants, studies have shown that the variants exhibit distinct expression profiles in both healthy brain tissue and in neuropathological conditions such as Parkinson disease, Lewy body disease and Alzheimer disease (Beyer et al., 2008; Cardo et al., 2014). Additional splice variants are predicted in the Ensembl database, including one encoding a 115 amino acid variant (ENST00000502987) comprised of exons 1-4 and the first 393 nucleotides of intron 4. This variant thus contains a unique 3'-UTR regulatory region however it is not known if any of these predicted splice variants produce functional polypeptides.

Studies measuring the expression levels of $\alpha$-synuclein in the prefrontal cortex of human alcohol misusers have shown conflicting findings: some studies show lower expression in this brain region (Etheridge et al., 2009, Janeczek et al., 2012; Lewohl et al., 2004, 2000), and several additional studies show no difference in expression relative to controls (Liu et al., 2004, 2006; Mayfield et al., 2002). This is likely due to the fact that these studies did not measure the expression of individual splice variants.

SNCA contains a number of single nucleotide polymorphisms (SNPs) and microsatellite repeat regions throughout the gene. Of particular interest are those in the promoter region and 3'UTR that have the potential to influence expression of the gene. The SNCA-Rep1 region is a microsatellite repeat $\sim 10 \mathrm{~kb}$ upstream of the translation start site. Variability in the length of this region has been associated with differences in expression. Specifically, there was a significantly higher frequency of the longer SNCA-Rep1 alleles in alcohol-dependent individuals that was correlated with higher $\alpha$-synuclein expression in blood (Bonsch et al., 2005b), whereas we found a higher frequency of the shorter $267 \mathrm{bp}$ allele in long-term alcohol misusers that was correlated with reduced expression of $\alpha$-synuclein in the dorsolateral prefrontal cortex (Janeczek et al., 2012).

The 3'-UTR of SNCA is highly conserved across species (Sotiriou et al., 2009) and few of the SNPs identified in this region exhibit sufficient heterozygosity for further study. However, alcohol-use phenotypes have been associated with SNCA 3'-UTR polymorphisms. Specifically, a haplotype block consisting of six SNPs (rs2736990, rs356168, rs356200, rs7684318, rs356221 and rs356219) was over-transmitted to alcohol cravers and the complementary haplotype block was over-transmitted to non-cravers (Foroud et al., 2007). An additional SNP, rs2736995 was also found 
to be associated with alcohol craving in this same study (Foroud et al., 2007). A study by Wilcox and colleagues found an association between SNPs in $\alpha$-synuclein and alcohol-evoked taste cue (BOLD) responses in brain regions associated with craving (Wilcox et al., 2013). The SNPs rs356168, rs2301134 and rs2736990 were found to be associated with a greater BOLD response (Wilcox et al., 2013). Thus, a key question is whether genetic variation, particularly within the 3'UTR, affects the expression of $\alpha$-synuclein. Here, we used real-time PCR to measure the expression of three splice variants, the two most-abundant variants, $S N C A-140$ and $S N C A-112$, as well as SNCA-115, a variant predicted to have a unique 3'-UTR, in the prefrontal cortex of alcohol misusers with and without cirrhosis of the liver and matched controls. A case-control approach was used to determine if a haplotype block in the SNCA 3'-UTR, along with other SNPs of interest, were associated with alcohol misuse. The approximate location of each of these SNPs in the SNCA gene is shown in Figure 1. We also investigated the influence of the SNCA 3'-UTR haplotype block on the expression of the gene.

\section{MATERIALS AND METHODS}

\subsection{Tissue Samples}

The Griffith University Human Ethics Committee provided ethical clearance for the project (MSC/02/06/HREC). The human brain tissue samples were collected by the Queensland Brain Bank, School of Chemistry and Molecular Biosciences, University of Queensland and the NSW Tissue Resource Centre, University of Sydney. Autopsied tissue samples were immersed in 10 vol of $0.32 \mathrm{M}$ sucrose and slowly frozen to best preserve the blocks (Dodd et al., 1986). The frozen samples were stored at $-80^{\circ} \mathrm{C}$ until the RNA isolation outlined below. The region selected for analysis was the dorsolateral prefrontal cortex (Brodmann areas 6 and 8).

\subsection{Case Selection}

For genotyping studies, DNA was extracted from 125 controls and 115 alcohol misusers. Subjects were classified by their daily average ethanol consumption in most of their adult life as reported in their medical records. Controls were those who consumed an average of $<20 \mathrm{~g}$ of ethanol per day or were teetotalers; alcohol misusers were those who had a mean intake of $>80 \mathrm{~g}$ of 
ethanol per day (for 30 years on average). All cases were of European origin. No schizophrenic case was included.

Expression studies were performed on a subset of individuals for whom brain tissue was available. This cohort consisted of 61 individuals: 24 controls and 37 alcohol misusers. Alcohol misusers were further divided into those without comorbid disease (uncomplicated alcohol misusers, 25 cases) and those with pathologically confirmed cirrhosis of the liver (cirrhotic alcohol misusers, 12 cases). Alcohol misusers with cirrhosis of the liver generally have more severe brain damage compared to those without liver cirrhosis (Zahr et al., 2011). Damage to the liver due to long term alcohol misuse results in a higher effective dose reaching the brain, and greater neuropathological damage (Harper, 1998). In addition, the expression profile in the prefrontal cortex of alcohol misusers with cirrhosis of the liver is distinct from those without cirrhosis of the liver (Liu et al., 2007).

Cases and controls were matched as closely as possible for gender, age at death and post mortem interval (PMI). No subject suffered from any other known condition at the time of death, nor did they take psychoactive drugs or medications for psychiatric conditions. Individuals with Wernicke-Korsakoff syndrome, hepatic encephalopathy or any other neurological condition were excluded. The gender, age, PMI and brain weight of the cases in each group are detailed in Table 1.

\subsection{RNA Isolation and Reverse Transcription}

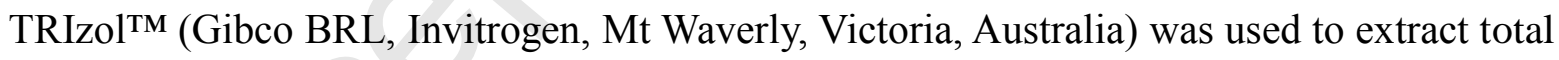
RNA according to the manufacturer's instructions. The quantity of RNA attained was measured by absorbance at $260 \mathrm{~nm}$ using a Nanodrop device (Thermo Scientific, Waltham, MA, USA). RNA quality was determined by visual inspection of electropherograms produced by the Agilent 2100 bio-analyzer (Palo Alto, CA, USA). High quality total RNA samples produce distinct 18S and 28S ribosomal peaks and lack multiple peaks corresponding to smaller RNA fragments. Whereas, a decrease in $28 \mathrm{~S}$ rRNA peak area, an increase in the baseline area below the 18S rRNA that spreads with smaller 28S rRNA fragments and a rise in the baseline between the 18S and 28S rRNA is indicative of a degraded sample. Degraded samples were excluded from further study. Total RNA was stored in aliquots of $20 \mu \mathrm{L}$ that were reverse-transcribed into cDNA by previously established methods (Ho et al., 2010; MacKay et al., 2011), diluted 1/50, and stored at $-80^{\circ} \mathrm{C}$ until required. 


\subsection{Primer Design}

Primer Express ${ }^{\circledR}$ v1.5 Software (Applied Biosystems, Mulgrave, Vic, Australia) was used to design the primers, which were synthesized by Sigma-Aldrich P/L (Castle Hill, NSW, Australia). Each primer set was verified for specificity using the Basic Local Alignment Search Tool (BLAST) from the GenBank non-redundant nucleotide sequence database (Altschul et al., 1997). To eliminate gDNA amplification, all assays were designed such that at least one primer spanned an exon boundary. For the SNCA-115 variant, the primers included part of the sequence of intron 4 . The primer sequences are shown in the supplementary Table $\mathrm{S} 1^{1}$. The efficiency of each primer pair was determined using previously established methods (Pfaffl, 2001).

\subsection{Real-Time PCR}

Real-time PCR was conducted on a 72 well rotor QIAGEN Rotor-Gene Q as previously described. In brief, each reaction contained $2 \mu \mathrm{L}$ of $1 / 50$ sample cDNA, $10 \mu \mathrm{L}$ of Bio-Rad SYBR Green PCR Master Mix (Bio-Rad Laboratories Pty Ltd, Gladesville, NSW, Australia), 300 nM of each primer in a final reaction volume of $20 \mu \mathrm{L}$. Duplicate amplifications were performed for each sample. No-template controls were included for each primer pair. As in previous studies, glyceralderhyde-3-phosphate dehydrogenase $(G A P D H)$ was used as the reference gene (Ho et al., 2010; MacKay et al., 2011). The expression of GAPDH was not affected by disease state (Analysis of Variance (ANOVA): $\left.F_{2,62}=0.932, P=0.399\right)$.

The differences between the mean $\mathrm{C}_{\mathrm{T}}$ values of the duplicates for each variant and the endogenous control gene, GAPDH were calculated to give $\triangle \mathrm{C}_{\mathrm{T}}$ values used for statistical analysis. The relative quantitation value was then expressed as $2^{-\Delta C}$ for presentation as outlined in previous studies (Ho et al., 2010; Livak and Schmittgen, 2001; MacKay et al., 2011). Statistical analysis was conducted using IBM SPSS Statistics 22 software (SPSS Inc, Chicago, IL, USA). ANOVA was followed, where appropriate, by the Tukey HSD post hoc tests. The effects of age at death, PMI and brain weight were determined using linear regression analysis. Where significant, covariance

\footnotetext{
${ }^{1}$ Supplementary material can be found by accessing the online version of this paper at http://dx.doi.org and by entering doi:...
} 
analysis (ANCOVA) was used to normalize that data and produce adjusted least-square mean and SEM values.

\subsection{DNA Extraction and Genotyping}

Phenol/chloroform extraction followed by ethanol precipitation was used to extract gDNA from human brain tissue (Sambrook et al., 1989). Five of the eight SNPs were genotyped using the High Resolution Melt (HRM) method with the Qiagen Rotor-Gene Q System and two SNPs with the Corbett Rotor-Gene ${ }^{\mathrm{TM}} 6000$ Analyzer according to the manufacturer's instructions.

For the SNPs analysed on the Qiagen system, each reaction consisted of $20 \mathrm{ng}$ of gDNA, 1× Colourless GoTaq ${ }^{\circledR}$ Flexi buffer, $2-3 \mathrm{mM}$ of $\mathrm{MgCl}_{2}, 400-800 \mu \mathrm{M}$ of dNTPs (Promega, Annandale, NSW, Australia), forward and reverse primers (see Table $\mathrm{S}^{2}$ ) at $300 \mathrm{nM}, 1.5 \mu \mathrm{M} \mathrm{SYTO}^{\circledR} 9$ green fluorescent nucleic acid stain (Invitrogen), $0.5 \mathrm{U}$ of GoTaq ${ }^{\circledR}$ Flexi Hot Start DNA Polymerase (Promega) in a final volume of $25 \mu \mathrm{l}$. Cycling conditions were: $95^{\circ} \mathrm{C}$ for $10 \mathrm{~min}, 95^{\circ} \mathrm{C}$ for $10 \mathrm{~s}$, "annealing temperature" for $10 \mathrm{~s}$, followed by an increase in temperature from $70^{\circ} \mathrm{C}$ to $80^{\circ} \mathrm{C}$ in increments of $0.1^{\circ} \mathrm{C}$. Annealing temperatures for each primer pair can be found in the supplementary material provided online; Table $S 1^{3}$. Rotor-Gene Q Software was used to analyse the resultant melt curves.

The rs2301134 and rs2736990 SNPs were genotyped using the HRM method with the Corbett Rotor-Gene $^{\mathrm{TM}} 6000$ as outlined in the $\mathrm{HRM}^{\mathrm{TM}}$ High Resolution Melt Assay Design and Analysis, CorProtocol $^{\mathrm{TM}}$ (Corbett Life Science, Mortlake, NSW, Australia). For the SNPs analysed on the Corbett system, each reaction mixture contained $1 \times$ Colourless GoTaq ${ }^{\circledR}$ Flexi buffer, $0.5 \mathrm{U}$ of GoTaq $^{\circledR}$ Flexi Hot Start DNA Polymerase, $3 \mu \mathrm{M} \mathrm{MgCl}_{2}, 0.2 \mu \mathrm{M}$ dNTPs (Promega), $1.5 \mu \mathrm{M}$ of $\mathrm{SYTO}^{\circledR} 9$ green fluorescent nucleic acid stain (Invitrogen), $0.3 \mu \mathrm{M}$ of both forward and reverse primers and $40 \mathrm{ng}$ of DNA in a final volume of $25 \mu 1$. Cycling conditions were: $95^{\circ} \mathrm{C}$ for $5 \mathrm{~min}$, $95^{\circ} \mathrm{C}$ for $5 \mathrm{~s}, 60^{\circ} \mathrm{C}$ for $10 \mathrm{~s}$, followed by an increase in temperature from $70^{\circ} \mathrm{C}$ to $88^{\circ} \mathrm{C}$ in

\footnotetext{
${ }^{2}$ Supplementary material can be found by accessing the online version of this paper at http://dx.doi.org and by entering doi:...

${ }^{3}$ Supplementary material can be found by accessing the online version of this paper at http://dx.doi.org and by entering doi:...
} 
increments of $0.1^{\circ} \mathrm{C}$. For each SNP, a representative sample of each genotype was sequenced to confirm that the correct product has been amplified. The samples were sequenced on an Applied Biosystems Hitachi ABI-3130 Genetic Analyzer.

Rs2736995 was genotyped using PCR-RFLP. The reaction mixture contained $0.2 \mu \mathrm{M}$ each of the forward and reverse primers, $1 \times$ Colourless GoTaq ${ }^{\circledR}$ Flexi buffer, $2 \mathrm{mM} \mathrm{MgCl} 2,0.1 \mu \mathrm{M}$ of dNTPs (Promega) and $20 \mathrm{ng}$ of gDNA in a final volume of $25 \mu \mathrm{L}$. Cycling conditions were: $95^{\circ} \mathrm{C}$ for $10 \mathrm{~min}$, then 40 cycles of $95^{\circ} \mathrm{C}$ for $30 \mathrm{~s}, 60^{\circ} \mathrm{C}$ for $30 \mathrm{~s}$ and $72^{\circ} \mathrm{C}$ for $30 \mathrm{~s}$, followed by a final extension step of $72^{\circ} \mathrm{C}$ for $5 \mathrm{~min}$. The PCR was performed using the Mastercycler ${ }^{\circledR}$ ep gradient $\mathrm{S}$ (Eppendorf, North Ryde, NSW, Australia). The PCR product was digested using BtsCI restriction enzyme (New England Biolabs Inc. Genesearch P/L, Arundel, QLD, Australia). The final reaction volume of $15 \mu$ l contained 12U of BtsCI, 1× enzyme NEBuffer 4 (New England Biolabs Inc. Genesearch P/L), $7 \mu$ l of PCR product and was incubated at $65^{\circ} \mathrm{C}$ for 16 hours. The digested products were separated by agarose gel electrophoresis.

\subsection{Statistical Analyses}

The allele and genotype frequencies for the eight SNPs were analysed using $\chi^{2}$, odds-ratio and the Hardy-Weinberg Equilibrium (HWE) test. These tests were performed with the HWE and Association Testing for SNPs in Case-Control Studies DeFinetti program (http://ihg.gsf.de/cgibin/hw/hwa1.pl). The Haploview v4.2 (Barrett et al., 2005) program was used for Linkage Equilibrium (LD) analysis $\left(D^{\prime}\right.$ and $\left.r^{2}\right)$, haplotype prediction and case-control haplotype frequency comparison. The analysis included $\chi^{2}$ tests with 10000 permutations to correct for multiple testing bias. For SNPs that were found to have a significant difference in allele and genotype frequencies between alcohol misusers and controls based on $\chi^{2}$ analysis, we then looked closely at the frequencies (Table 3) to choose alleles that may increase or decrease the chance of an individual developing an alcohol misuse phenotype OR being in the control or alcohol misuser group. These would be defined as 'risk' and 'protective' alleles. To determine if any 'risk' alleles/haplotypes identified from the frequency results predict higher odds of an individual having an alcohol misuse phenotype, each individual that had at least one copy of the 'risk' allele/haplotype was assigned a value of 1 and all other samples were coded as 0 . Logistic regression was then performed using IBM SPSS Statistics 22 software (SPSS Inc). The model was adjusted for sex, as initial analysis 
showed correlations with the case/control variable $(r=0.188, P=0.003)$. We then used the independent samples $t$-test (SPSS Inc) to investigate the effect of SNCA 3'-UTR haplotypes on $\alpha$ synuclein expression. We used the same method to determine if any 'protective' alleles or haplotypes identified from the frequency results predicted decreased odds of an individual having an alcohol misuse phenotype. Differences were considered statistically significant at $P<0.05$.

\section{RESULTS}

\subsection{Expression Study}

We measured the expression of the two most abundant $\alpha$-synuclein transcripts, the wild type SNCA-140 variant, the shorter SNCA-112 variant, as well as the SNCA-115 variant, in the dorsolateral prefrontal cortex of chronic alcohol misusers and age- and sex-matched controls using real-time PCR.

Case information is outlined in Table 1. Alcohol misusers and controls were matched as closely as possible for PMI and age at death. There was no significant difference in age at death or PMI between the groups (Age: $F_{2,58}=2.243, P=0.115$; PMI: $F_{2,58}=0.408, P=0.667$ ). Overall, mean brain weights were significantly different across groups $\left(F_{2,58}=3.163, P=0.05\right)$. Post hoc testing showed that brain weights of the cirrhotic alcohol misusers group were significantly lower than the uncomplicated alcohol misusers group $(P=0.05)$ but not when compared with controls $(P$ $=0.088)$. To determine if the expression of any $\alpha$-synuclein transcript was correlated with age at death, PMI, or brain weight, linear regression was performed on each parameter. Regression analysis was carried out using all subjects combined and with subjects separated according to alcohol status (controls vs. combined alcohol misusers).

Overall there was no significant correlation between the expression of any splice variant and age at death in combined subjects (Table 2), or for cases separated into their respective groups, with the exception of $S N C A-115$, which was significantly correlated with age at death in control subjects only $\left(F_{1,22}=7.447, P=0.012\right)$. Inspection showed that the expression of $S N C A-115$ increased with age at death. There was no such correlation in combined alcohol misusers $\left(F_{1,35}=0.359, P=\right.$ 0.553). ANCOVA on the expression of SNCA-115 using age at death as the covariate did not alter 
the pattern of effects observed with ANOVA alone. As the case groups did not differ significantly on age at death, a simple factorial ANOVA was appropriate to analyse the data.

There was no significant correlation between the expression of any splice variant and PMI for combined cases although this did approach significance for SNCA-115 (Table 2). There was also no significant correlation between the expression of any splice variant and PMI for cases separated into their respective groups, with the exception of $S N C A-115$, which was significantly correlated with PMI in combined alcohol misusers only $\left(F_{1,35}=5.134, P=0.03\right)$. Inspection showed that the expression of SNCA-115 increased with longer PMIs. There was no such correlation in control subjects $\left(F_{1,22}=0.096, P=0.759\right)$. ANCOVA on the expression of SNCA-115 with PMI as the covariate did not alter the pattern of effects observed with ANOVA alone. As the case groups did not differ significantly on PMI, a simple factorial ANOVA was appropriate to analyse the data.

The expression of each splice variant was significantly correlated with brain weight in combined subjects (Table 2). When case groups were analyzed separately, expression values for the SNCA-140 and SNCA-115 transcripts were significantly correlated with brain weight in combined alcohol misusers $\left(S N C A-140: F_{1,35}=5.151, P=0.029 ; S N C A-115: F_{1,35}=12.796, P=0.001\right)$ but not in controls $\left(S N C A-140: F_{1,22}=4.709, P=0.041 ; S N C A-115: F_{1,22}=0.357, P=0.557\right)$. There was no significant correlation with the $S N C A-112$ variant in combined alcohol misusers or controls (alcohol misusers: $F_{1,35}=3.086, P=0.09$; controls: $F_{1,22}=0.736, P=0.40$ ). Since the case groups differed significantly in brain weight we performed all statistical tests using both a simple factorial ANOVA and an ANCOVA with brain weight as the covariate. The same pattern of effects was observed in both analyses.

The expression of SNCA-140 (ANCOVA: $F_{3,57}=7.919, P<0.001$ ), SNCA-112 (ANCOVA: $F_{3,57}=2.801, P=0.048$ ), and SNCA-115 (ANCOVA: $F_{3,57}=6.062, P=0.001$ ) was significantly different between groups. The expression of the SNCA-140 transcript was significantly lower in cirrhotic alcohol misusers compared with both controls (Tukey HSD, $P=0.001$ ) and uncomplicated alcohol misusers (Tukey HSD, $P=0.003$ ). The expression of the $S N C A-112$ variant was significantly lower in cirrhotic alcohol misusers compared with controls (Tukey HSD, $P=0.048$ ) but not with uncomplicated alcohol misusers (Tukey HSD, $P=0.087$ ). Conversely, the expression of the SNCA-115 variant was significantly greater in cirrhotic alcohol misusers compared with both 
controls (Tukey HSD, $P=0.008$ ) and uncomplicated alcohol misusers (Tukey HSD, $P=0.012$; Figure 2).

\subsection{Genotyping Study}

To investigate the potential influence of polymorphisms in the SNCA 3'-UTR and elsewhere in the gene, we genotyped our population for the eight SNPs shown in Figure 1. Six of the eight SNPs (rs356221, rs356219, rs7684318, rs2736990, rs2736995 and rs2301134) were in HWE $(P=0.47, P=0.46, P=1.00, P=1.00, P=0.67$ and $P=1.00$ respectively); two (rs356168 and rs356200) were not $(P=0.018$ and $P=0.011$ respectively $)$.

The allele and genotype frequencies differed significantly between alcohol misusers and controls for rs356221, rs356219 and rs2736995 (Table 3), where the T allele and TT genotype were more frequent in alcohol misusers than in controls for rs356221 and rs2736995, and the A allele and AA genotype were more frequent in alcohol misusers than in controls for rs356219. No significant difference was found between alcohol misusers and controls for the other SNPs (rs7684318, rs2736990, rs2301134, rs356168 and rs356200). A number of the SNPs in our study (rs2736990, rs356168, rs356200, rs7684318, rs356221 and rs356219) have previously been associated with alcohol craving as part of a 3'-UTR haplotype block (Foroud et al., 2007). Therefore, we performed further analysis to establish if this haplotype existed in our population. The Haploview program was used to calculate LD between all of the SNPs. Strong LD was found between rs356219 and rs356221 $\left(D^{\prime}=0.949 ; r^{2}=0.587\right.$; Figure 3$)$. Haplotype analysis showed that the frequency of haplotype A-T was significantly lower in controls (Table 4), whereas a significantly lower frequency of haplotype G-A was seen in alcohol misusers. No significant difference was seen for the haplotype A-A. The frequency of the T-G haplotype in our population was less than $1 \%$ and therefore it was excluded from further analysis. Strong LD was also observed between rs356168 and rs356221 $\left(D^{\prime}=0.98 ; r^{2}=0.789\right.$; Figure 3$)$, however as rs356168 did not follow HWE this result only provides weak support of a link between rs356168 and rs356221, and was therefore excluded from further analysis. 


\subsection{Determining Potential Risk and Protective Alleles and Haplotypes}

The rs356219/rs356221 A and T alleles were identified as potential 'risk' alleles for alcohol misuse due to their allele frequencies and, as mentioned previously, the haplotype A-T frequency was found to be significantly lower in controls (Table 4). However, logistic regression did not show that subjects with at least one copy of the rs356219 A allele and rs356221 T allele were more likely to have an alcohol misuse phenotype (adjusted odds ratio $\left(O R_{a d j}\right)=1.467, d f=1, P=0.255,95 \%$ confidence interval $(C I)=0.758-2.838)$. When examined separately, no increased risk was found for either allele (rs356219: $O R_{a d j}=1.992, d f=1, P=0.114,95 \% C I=0.848-4.679$; rs356221: $\left.O R_{a d j}=1.426, d f=1, P=0.282,95 \% C I=0.747-2.722\right)$.

The frequency of the rs2736995 $\mathrm{T}$ allele was significantly greater in alcohol misusers, and was therefore identified as a potential 'risk' allele for alcohol misuse. We termed the T allele a 'risk' allele to determine if individuals with at least one copy of the allele were more likely to be an alcohol misuser. However, these individuals were not significantly more likely to be an alcohol misuser $\left(O R_{a d j}=2.145, d f=1, P=0.142,95 \% C I=0.775-5.935\right)$.

To determine if the 3'-UTR haplotype block previously identified by Foroud and colleagues (Foroud et al., 2007) was associated with alcohol misuse in our population, we constructed haplotypes in two ways by grouping individuals on the basis of whether they had a copy of the risk haplotype or not. The first approach involved using tag SNPs to represent all the haplotypes present in the haplotype block to estimate association with an alcohol misuse phenotype. As most of the SNPs genotyped in our study fell into Foroud's "block 3" (Foroud et al., 2007) we focused on the three tag SNPs that were significantly correlated with craving in that study. The second approach involved overlapping groups of three adjacent SNPs to form an extended haplotype. One of these haplotypes was over-transmitted to alcohol cravers (G-G-T-C-A-G, 10\%) and its complementary haplotype (A-A-C-T-T-A, 50\%) was over-transmitted to non-craving alcoholics (Foroud et al., 2007).

Logistic regression showed that subjects with all three tag SNPs were not more likely to have an alcohol misuse phenotype (C-A-G: $O R_{a d j}=0.569, d f=1, P=0.186,95 \% C I=0.247-$ 1.312; T-A-A: $O R_{a d j}=0.611, d f=1, P=0.094,95 \% \quad C I=0.343-1.088 ;$ T-T-A: $O R_{a d j}=1.327$, $d f=1, P=0.424,95 \% C I=0.663-2.655)$. Furthermore, neither the extended haplotype over- 
transmitted to craving individuals, nor the haplotype over-transmitted to non-craving individuals was more likely to have an alcohol misuse phenotype $\left(O R_{a d j}=0.350, d f=1, P=0.080,95 \% C I=\right.$ $0.108-1.133 ; O R_{a d j}=0.780, d f=1, P=0.389,95 \% C I=0.443-1.372$ respectively).

The rs356219/rs356221 G and A alleles were identified as potential 'protective' alleles for alcohol misuse due to their allele frequencies. Also, as mentioned above, a significantly lower frequency of the haplotype consisting of these protective G-A alleles was seen in alcohol misusers (Table 4). Logistic regression showed that subjects with at least one copy of the rs356219 G allele and rs356221 A allele were less likely to have an alcohol misuse phenotype $\left(O R_{a d j}=0.451, d f=1\right.$, $P=0.004,95 \% C I=0.263-0.774)$. When examined separately, both alleles were also found to be protective (rs356219: $O R_{a d j}=0.421, d f=1, P=0.002,95 \% C I=0.245-0.725 ;$ rs356221: $O R_{a d j}=$ $0.452, d f=1, P=0.009,95 \% C I=0.250-0.819)$.

\subsection{Determining the Influence of Genotype on $\alpha$-Synuclein Expression}

Partitioning the expression data according to each individual's $S N C A$ genotype had no effect for any of the SNPs individually or in combination. Cases were again separated into groups for logistic regression on the basis of the previously established 3'-UTR haplotype (Foroud et al., 2007) as well as the 3'-UTR haplotype found in our population. Within the expression cohort, only one control individual was predicted to have the haplotype that was associated with cravers, while twenty individuals ( 8 controls, 12 alcohol misusers) were predicted to have the complementary haplotype associated with non-cravers. Furthermore, 26 alcohol misusers and 17 control individuals had the haplotype found in our study population. There was no significant difference in $\alpha$-synuclein expression of any of the transcripts when compared on this basis (Table 5).

\section{DISCUSSION}

We measured the expression of three $\alpha$-synuclein splice variants in the prefrontal cortex of human alcohol misusers. The expression of the SNCA-140 and SNCA-112 variants was significantly lower in the prefrontal cortex of cirrhotic alcohol misusers compared with controls. Conversely, the expression of the SNCA-115 variant, was significantly higher in cirrhotic alcohol misusers compared with controls. There was no significant difference in the expression of the SNCA-140, SNCA-112 or SNCA-115 variants between uncomplicated alcohol misusers and controls. In previous 
studies $\alpha$-synuclein has been shown to be differentially regulated in the prefrontal cortex in microarray (Lewohl et al., 2000) and proteomic (Lewohl et al., 2004) studies; however, neither of these techniques is definitive for highly homologous transcripts. Neuropathological studies have shown that chronic alcohol misuse results in significant brain damage which is exacerbated in individuals with concomitant liver cirrhosis (Harper and Kril). This study is the first to report gene expression changes of individual splice variants in the brains of human alcohol misusers. However, it is not possible to determine whether the changes in $\alpha$-synuclein expression observed in our study are the result of cirrhosis per se, reflect the extent of brain damage observed in cirrhotic alcohol misusers, or is the result of greater alcohol exposure in these individuals.

$\alpha$-Synuclein is expressed in response to a number of stimuli, including apoptotic signals, oxidative stress, and excitotoxicity, and is dysregulated in neurodegenerative diseases such as Parkinson and Alzheimer disease (Sidhu et al., 2004). Our study provides strong evidence that $\alpha$ synuclein splice variants are differentially regulated following chronic alcohol misuse and that this dysregulation is selective for the pathologically susceptible prefrontal cortex. Previous studies have shown that these variants exhibit distinct expression profiles in both healthy brain tissue and in neuropathological conditions such as Parkinson disease, Lewy body disease and Alzheimer disease (Beyer et al., 2008; Cardo et al., 2014). The functional differences between these splice variants remain unclear, however, it is likely that the shorter variants produce a protein with a different structure to the wild-type protein which may in turn affect their chaperone activity and aggregation properties (Beyer et al., 2008; Bungeroth et al., 2014).

$\alpha$-Synuclein is a negative regulator of dopamine release (Abeliovich et al., 2000; Perez et al., 2002). It alters dopamine synthesis via the transcriptional regulation of genes involved in dopamine synthesis (Baptista et al., 2003), and influences dopamine re-uptake by the dopamine transporter (Wersinger and Sidhu, 2003). Complete or partial knockdown of $\alpha$-synuclein in laboratory animals increases dopamine release (Abeliovich et al., 2000; Yavich et al., 2004), reduces dopamine uptake (Fountaine and Wade-Martins, 2007), and sensitizes the brain reward system (Oksman et al., 2006). Thus, reduced expression of the $S N C A-140$ and $S N C A-112$ variants may attenuate dopaminergic neurotransmission in the prefrontal cortex. In turn, this may increase the risk of neuronal damage and the inability for neurons to adapt to long-term alcohol exposure 
(Baptista et al., 2003; Yavich et al., 2004). $\alpha$-Synuclein has dual roles in neuroprotection and neurotoxicity (Seo et al., 2002); the increased expression of SNCA-115 may be one mechanism by which neurons adapt to the presence of alcohol.

The expression of $\alpha$-synuclein is modulated by exposure to alcohol and other drugs of misuse in both animal models and human subjects. Actively drinking and recently withdrawn alcohol misusers have elevated $\alpha$-synuclein serum levels that correlate with increased craving for alcohol (Bonsch et al., 2005a, 2004). Primates that self-administer alcohol have a three-fold higher expression of $\alpha$-synuclein than alcohol-naïve controls (Walker and Grant, 2006). Rats selectively bred for high alcohol preference have altered expression of $S N C A$ as a result of a single polymorphic variant in its 3'-UTR (Liang et al., 2003). The three splice variants measured in our study differ in one key aspect. SNCA-140 and SNCA-112 share the same 3'-UTR although it is likely that the length of the 3'-UTR varies between these transcripts. The SNCA-115 variant has a unique 3'-UTR coded by part of intron 4. One potential mechanism by which these transcripts may be regulated could be through sequence variation in the 3 '-UTR of the gene.

Thus, we examined the association between eight polymorphisms in the SNCA gene and an alcohol misuse phenotype, and the influence of genetic variation in these polymorphisms on the expression of $\alpha$-synuclein splice variants. Allele and genotype frequencies were found to differ significantly between alcohol misusers and controls for three of the SNPs: rs356219, rs356221 and rs2736995. We performed further analysis to determine if LD existed in our population and found strong LD between rs356219 and rs356221. Our results showed that both the A (rs356219) and T (rs356221) alleles were 'risk' alleles for alcohol misuse and that the frequency of haplotype A-T was significantly lower in controls, whereas a significantly lower frequency of haplotype G-A was seen in alcohol misusers. The G (rs356219) and A (rs356221) alleles that make up the G-A haplotype, are both 'protective' alleles and the frequencies of both these alleles were lower in alcohol misusers. We therefore expected to see a higher frequency of the G-A haplotype in controls. We did not see evidence of the A and $\mathrm{T}$ alleles or haplotype being associated with an alcohol misuse phenotype in our population. It might be the case that two risk alleles are not enough to significantly increase susceptibility. As these two SNPs have previously been found to be part of haplotype block by Foroud and colleagues (2007), perhaps a haplotype consisting of a greater 
number of risk alleles is required to increase an individual's risk of being an alcohol misuser and produce a significant odds ratio. However we did find that the $\mathrm{G}$ and $\mathrm{A}$ alleles as well as the G-A haplotype decreased the odds of an individual having an alcohol misuse phenotype. These results suggest that individuals with either of these alleles may be protected.

The other SNPs that have been reported to be in the same haplotype block (Foroud et al., 2007), were not in LD in our population. It is possible that single polymorphisms or small haplotypes do not have sufficient power to detect association (Foroud et al., 2007). We also made comparisons between individuals using both the haplotype found in our population and the three tag SNP haplotypes corresponding to those previously published (Foroud et al., 2007). However, we did not find evidence of risk alleles that were associated with an alcohol misuse phenotype in our population.

Although we found no evidence that sequence variation in the 3'-UTR of the gene influenced the expression of $\alpha$-synuclein splice variants, this does not preclude the involvement of the 3'-UTR in the regulation of the gene. MiRNAs are known regulators of gene expression that exert their influence through interaction with the 3'-UTR. The interactions between miRNAs and their target genes can be altered in both a direct and indirect manner, with the potential to enhance binding affinity of the miRNA to its target, to eliminate a binding site, to change the structure of the 3'-UTR and prevent access to the binding site as well as create new, illegitimate binding sites. Thus, genetic variation in the 3'-UTR that can modify miRNA binding target sites may lead to changes in post-transcriptional regulation of the gene (Chen et al., 2008; Georges et al., 2007). Future studies should investigate the miRNA regulation of $S N C A$ to provide further insight into the pathophysiology of chronic alcoholism, focusing particularly on the effect of 3'-UTR length and genetic variation on miRNA-target interactions and expression of the gene and the consequences this has on mediating the pathological effects of chronic alcoholism.

This study demonstrates that alcohol differentially alters levels of the individual $\alpha$-synuclein splice variants in the prefrontal cortex of alcohol misusers with cirrhosis of the liver. Although we did see significant differences in frequencies for rs356219, rs356221 and rs2736995, and LD between rs356219 and rs356221, no significant haplotypes were found to predispose individuals to an alcohol misuse phenotype or have an effect on $\alpha$-synuclein gene expression. However, our 
results suggest that the rs356219/356221 G-A haplotype may decrease the chance of having an alcohol misuse phenotype. Understanding the mechanisms that control $\alpha$-synuclein expression is critical to identifying its role in neurodegeneration and the potential for modulating its expression levels in vivo as a therapy for neurodegenerative diseases, including chronic alcohol misuse. 


\section{FIGURE LEGEND}

Figure 1. A representation of the human $\alpha$-synuclein gene as in Xia et al. (2001) and adapted from (Janeczek and Lewohl, 2013). The exons (Ex) and introns (Int) are represented by the black/grey boxes and white boxes respectively. The start (ATG) and stop (TAA) codons have been marked. For the purpose of this diagram introns 2 and 4 have been collapsed due to their size, as shown by the two diagonal lines. The diagram shows the approximate positions of the eight polymorphisms included in this study and the Foroud et al. (2007) study. These polymorphisms have been associated with alcohol misuse, alcohol craving or alcohol dependence in previous studies (Agrawal et al., 2012; Bonsch et al., 2005b; Clarimon et al., 2007; Foroud et al., 2007; Janeczek et al., 2012).

Figure 2. Relative mRNA expression levels of the three transcript variants SNCA-140, SNCA-112 and SNCA-115 in controls, alcohol misuse and cirrhotic-alcohol misuse cases. $\Delta \mathrm{C}_{\mathrm{T}}$ values have been converted to $2^{-\Delta^{\mathrm{CT}}}$ values. The expression of SNCA-140 was significantly lower in cirrhotic alcohol misusers than in both the controls and uncomplicated alcohol misusers. The expression of the SNCA-112 variant was significantly lower in cirrhotic alcohol misusers than in controls only. The expression of the $S N C A-115$ variant was significantly greater in cirrhotic alcohol misusers compared with both controls and uncomplicated alcohol misusers. *Significant results $(P<0.05$ vs. controls).

Figure 3. A visual presentation created by Haploview v4.2 (Barrett et al., 2005) of the pairwise LD found between the eight SNPs in this study. Estimates of LD for each pair are represented by the $D^{\prime}$ value within the squares, the darker squares indicating strong evidence of LD. Strong LD was found between rs356219 and rs356221 $\left(D^{\prime}=0.949 ; r^{2}=0.587\right)$. 


\section{REFERENCES}

Abeliovich, A., Schmitz, Y., Farinas, I., Choi-Lundberg, D., Ho, W.H., Castillo, P.E., Shinsky, N., Verdugo, J.M., Armanini, M., Ryan, A., Hynes, M., Phillips, H., Sulzer, D., Rosenthal, A., 2000. Mice lacking alpha-synuclein display functional deficits in the nigrostriatal dopamine system. Neuron 25, 239-252.

Agrawal, A., Wetherill, L., Bucholz, K.K., Kramer, J., Kuperman, S., Lynskey, M.T., Nurnberger, J.I., Jr., Schuckit, M., Tischfield, J.A., Edenberg, H.J., Foroud, T., Bierut, L.J., 2012. Genetic influences on craving for alcohol. Addict. Behav. 38, 1501-1508.

Altschul, S.F., Madden, T.L., Schaffer, A.A., Zhang, J., Zhang, Z., Miller, W., Lipman, D.J., 1997. Gapped BLAST and PSI-BLAST: a new generation of protein database search programs. Nucleic Acids Res. 25, 3389-3402.

Anni, H., Israel, Y., 2002. Proteomics in alcohol research. Alcohol Res. Health 26, 219-232.

Baptista, M.J., O'Farrell, C., Daya, S., Ahmad, R., Miller, D.W., Hardy, J., Farrer, M.J., Cookson, M.R., 2003. Co-ordinate transcriptional regulation of dopamine synthesis genes by alpha-synuclein in human neuroblastoma cell lines. J. Neurochem. 85, 957-968.

Barrett, J.C., Fry, B., Maller, J., Daly, M.J., 2005. Haploview: analysis and visualization of LD and haplotype maps. Bioinformatics 21, 263-265.

Beyer, K., Domingo-Sabat, M., Humbert, J., Carrato, C., Ferrer, I., Ariza, A., 2008. Differential expression of alpha-synuclein, parkin, and synphilin-1 isoforms in Lewy body disease. Neurogenetics 9, 163-172.

Bonsch, D., Greifenberg, V., Bayerlein, K., Biermann, T., Reulbach, U., Hillemacher, T., Kornhuber, J., Bleich, S., 2005a. Alpha-synuclein protein levels are increased in alcoholic patients and are linked to craving. Alcohol. Clin. Exp. Res. 29, 763-765. 
Bonsch, D., Lederer, T., Reulbach, U., Hothorn, T., Kornhuber, J., Bleich, S., 2005b. Joint analysis of the NACP-REP1 marker within the alpha synuclein gene concludes association with alcohol dependence. Hum. Mol. Genet. 14, 967-971.

Bonsch, D., Reulbach, U., Bayerlein, K., Hillemacher, T., Kornhuber, J., Bleich, S., 2004. Elevated alpha synuclein mRNA levels are associated with craving in patients with alcoholism. Biol. Psychiatry 56, 984-986.

Bungeroth, M., Appenzeller, S., Regulin, A., Volker, W., Lorenzen, I., Grotzinger, J., Pendziwiat, M., Kuhlenbaumer, G., 2014. Differential aggregation properties of alpha-synuclein isoforms. Neurobiol. Aging 35, 1913-1919.

Cardo, L.F., Coto, E., de Mena, L., Ribacoba, R., Mata, I.F., Menendez, M., Moris, G., Alvarez, V., 2014. Alpha-synuclein transcript isoforms in three different brain regions from Parkinson's disease and healthy subjects in relation to the SNCA rs356165/rs11931074 polymorphisms. Neurosci. Lett. $562,45-49$.

Chen, K., Song, F., Calin, G.A., Wei, Q., Hao, X., Zhang, W., 2008. Polymorphisms in microRNA targets: a gold mine for molecular epidemiology. Carcinogenesis 29, 1306-1311.

Clarimon, J., Gray, R.R., Williams, L.N., Enoch, M.A., Robin, R.W., Albaugh, B., Singleton, A., Goldman, D., Mulligan, C.J., 2007. Linkage disequilibrium and association analysis of alphasynuclein and alcohol and drug dependence in two American Indian populations. Alcohol. Clin. Exp. Res. 31, 546-554.

Crews, F.T., Buckley, T., Dodd, P.R., Ende, G., Foley, N., Harper, C., He, J., Innes, D., Loh el, W., Pfefferbaum, A., Zou, J., Sullivan, E.V., 2005. Alcoholic neurobiology: changes in dependence and recovery. Alcohol. Clin. Exp. Res. 29, 1504-1513.

Dodd, P.R., Hardy, J.A., Baig, E.B., Kidd, A.M., Bird, E.D., Watson, W.E., Johnston, G.A., 1986. Optimization of freezing, storage, and thawing conditions for the preparation of metabolically active synaptosomes from frozen rat and human brain. Neurochem. Pathol. 4, 177-198. 
Etheridge, N., Lewohl, J.M., Mayfield, R.D., Harris, R.A., Dodd, P.R., 2009. Synaptic proteome changes in the superior frontal gyrus and occipital cortex of the alcoholic brain. Proteomics Clin. Appl. 3, 730-742.

Foroud, T., Wetherill, L.F., Liang, T., Dick, D.M., Hesselbrock, V., Kramer, J., Nurnberger, J., Schuckit, M., Carr, L., Porjesz, B., Xuei, X., Edenberg, H.J., 2007. Association of alcohol craving with <-synuclein (SNCA). Alochol. Clin. Exp. Res. 31, 537-545.

Fountaine, T.M., Wade-Martins, R., 2007. RNA interference-mediated knockdown of alphasynuclein protects human dopaminergic neuroblastoma cells from MPP(+) toxicity and reduces dopamine transport. J. Neurosci. Res. 85, 351-363.

Georges, M., Coppieters, W., Charlier, C., 2007. Polymorphic miRNA-mediated gene regulation: contribution to phenotypic variation and disease. Curr. Opin. Genet. Dev. 17, 166-176.

Harper, C., 1998. The neuropathology of alcohol-specific brain damage, or does alcohol damage the brain? J. Neuropathol. Exp. Neurol. 57, 101-110.

Harper, C., Kril, J., 1989. Patterns of neuronal loss in the cerebral cortex in chronic alcoholic patients. J. Neurol. Sci. 92, 81-89.

Harper, C., Kril, J., 1991. If you drink your brain will shrink. Neuropathological considerations. Alcohol Alcohol. Suppl. 1, 375-380.

Ho, A.M., MacKay, R.K., Dodd, P.R., Lewohl, J.M., 2010. Association of polymorphisms in RGS4 and expression of RGS transcripts in the brains of human alcoholics. Brain Res. 1340, 1-9.

Janeczek, P., Lewohl, J.M., 2013. The role of alpha-synuclein in the pathophysiology of alcoholism. Neurochem. Int. 63, 154-162.

Janeczek, P., Mackay, R.K., Lea, R.A., Dodd, P.R., Lewohl, J.M., 2012. Reduced expression of alpha-synuclein in alcoholic brain: influence of SNCA-Rep1 genotype. Addict. Biol. 19, 509-515. 
Levey, D.F., Le-Niculescu, H., Frank, J., Ayalew, M., Jain, N., Kirlin, B., Learman, R., Winiger, E., Rodd, Z., Shekhar, A., Schork, N., Kiefe, F., Wodarz, N., Muller-Myhsok, B., Dahmen, N., Nothen, M., Sherva, R., Farrer, L., Smith, A.H., Kranzler, H.R., Rietschel, M., Gelernter, J., Niculescu, A.B., 2014. Genetic risk prediction and neurobiological understanding of alcoholism. Transl. Psychiatry 4, e391.

Lewohl, J.M., Van Dyk, D.D., Craft, G.E., Innes, D.J., Mayfield, R.D., Cobon, G., Harris, R.A., Dodd, P.R., 2004. The application of proteomics to the human alcoholic brain. Ann. N. Y. Acad. Sci. $1025,14-26$.

Lewohl, J.M., Wang, L., Miles, M.F., Zhang, L., Dodd, P.R., Harris, R.A., 2000. Gene expression in human alcoholism: microarray analysis of frontal cortex. Alcohol. Clin. Exp. Res. 24, 1873-1882.

Liang, T., Spence, J., Liu, L., Strother, W.N., Chang, H.W., Ellison, J.A., Lumeng, L., Li, T.K., Foroud, T., Carr, L.G., 2003. alpha-Synuclein maps to a quantitative trait locus for alcohol preference and is differentially expressed in alcohol-preferring and -nonpreferring rats. Proc. Natl. Acad. Sci. U. S. A. 100, 4690-4695.

Liu, J., Lewohl, J.M., Dodd, P.R., Randall, P.K., Harris, R.A., Mayfield, R.D., 2004. Gene expression profiling of individual cases reveals consistent transcriptional changes in alcoholic human brain. J. Neurochem. 90, 1050-1058.

Liu, J., Lewohl, J.M., Harris, R.A., Dodd, P.R., Mayfield, R.D., 2007. Altered gene expression profiles in the frontal cortex of cirrhotic alcoholics. Alcohol. Clin. Exp. Res. 31, 1460-1466.

Liu, J., Lewohl, J.M., Harris, R.A., Iyer, V.R., Dodd, P.R., Randall, P.K., Mayfield, R.D., 2006. Patterns of gene expression in the frontal cortex discriminate alcoholic from nonalcoholic individuals. Neuropsychopharmacology 31, 1574-1582.

Livak, K.J., Schmittgen, T.D., 2001. Analysis of relative gene expression data using real-time quantitative PCR and the $2^{-\otimes \otimes C T}$ method. Methods $25,402-408$. 
MacKay, R.K., Colson, N., Dodd, P.R., Lewohl, J.M., 2011. Differential expression of 14-3-3 isoforms in human alcoholic brain. Alcohol. Clin. Exp. Res. In Press.

Mayfield, R.D., Lewohl, J.M., Dodd, P.R., Herlihy, A., Liu, J., Harris, R.A., 2002. Patterns of gene expression are altered in the frontal and motor cortices of human alcoholics. J. Neurochem. 81, 802813.

Miranda, R.C., Pietrzykowski, A.Z., Tang, Y., Sathyan, P., Mayfield, D., Keshavarzian, A., Sampson, W., Hereld, D., 2010. MicroRNAs: master regulators of ethanol abuse and toxicity? Alcohol. Clin. Exp. Res. 34, 575-587.

Nestler, E.J., 2000. Genes and addiction. Nat. Genet. 26, 277-281.

Nestler, E.J., Aghajanian, G.K., 1997. Molecular and cellular basis of addiction. Science 278, 5863.

Oksman, M., Tanila, H., Yavich, L., 2006. Brain reward in the absence of alpha-synuclein. Neuroreport 17, 1191-1194.

Perez, R.G., Waymire, J.C., Lin, E., Liu, J.J., Guo, F., Zigmond, M.J., 2002. A role for alphasynuclein in the regulation of dopamine biosynthesis. J. Neurosci. 22, 3090-3099.

Pfaffl, M.W., 2001. A new mathematical model for relative quantification in real-time RT-PCR. Nucleic Acids Res. 29, e45.

Sambrook, J., Fritsch, E.F., Maniatis, T., 1989. Gel electrophoresis of DNA. In: Nolan, C. (Ed.), Molecular Cloning: A Laboratory Manual. Cold Spring Harbour Press, Cold Spring Harbour.

Seo, J.H., Rah, J.C., Choi, S.H., Shin, J.K., Min, K., Kim, H.S., Park, C.H., Kim, S., Kim, E.M., Lee, S.H., Lee, S., Suh, S.W., Suh, Y.H., 2002. Alpha-synuclein regulates neuronal survival via Bcl2 family expression and PI3/Akt kinase pathway. FASEB J. 16, 1826-1828.

Sidhu, A., Wersinger, C., Moussa, C.E., Vernier, P., 2004. The role of alpha-synuclein in both neuroprotection and neurodegeneration. Ann. N. Y. Acad. Sci. 1035, 250-270. 
Sotiriou, S., Gibney, G., Baxevanis, A.D., Nussbaum, R.L., 2009. A single nucleotide polymorphism in the $3^{\prime}$ UTR of the SNCA gene encoding alpha-synuclein is a new potential susceptibility locus for Parkinson disease. Neurosci. Lett. 461, 196-201.

Walker, S.J., Grant, K.A., 2006. Peripheral blood alpha-synuclein mRNA levels are elevated in cynomolgus monkeys that chronically self-administer ethanol. Alcohol 38, 1-4.

Wersinger, C., Sidhu, A., 2003. Attenuation of dopamine transporter activity by alpha-synuclein. Neurosci. Lett. 340, 189-192.

Wilcox, C.E., Claus, E.D., Blaine, S.K., Morgan, M., Hutchison, K.E., 2013. Genetic variation in the alpha synuclein gene (SNCA) is associated with BOLD response to alcohol cues. J. Stud. Alcohol Drugs 74, 233-244.

Yavich, L., Tanila, H., Vepsalainen, S., Jakala, P., 2004. Role of alpha-synuclein in presynaptic dopamine recruitment. J. Neurosci. 24, 11165-11170.

Zahr, N.M., Kaufman, K.L., Harper, C.G., 2011. Clinical and pathological features of alcoholrelated brain damage. Nat. Rev. Neurol. 7, 284-294. 
Table 1. Case information - Expression study.

\begin{tabular}{lllll}
\hline Group & N & Age (y) & PMI (h) & Brain weight (g) \\
\hline Control (13 female, 11 male) & 24 & $59.00 \pm 2.81$ & $30.58 \pm 5.01$ & $1328.96 \pm 24.95$ \\
Alcohol misuser (10 female, 15 male) & 25 & $51.75 \pm 2.83$ & $30.16 \pm 3.40$ & $1339.48 \pm 26.03$ \\
$\begin{array}{l}\text { Cirrhotic alcohol misuser (6 female, 6 } \\
\text { male) }\end{array}$ & 12 & $60.33 \pm 4.19$ & $24.26 \pm 6.08$ & $1234.50 \pm 32.94$ \\
\hline
\end{tabular}


Table 2: Regression Analysis

\begin{tabular}{lll}
\hline Age at Death & & \\
\hline Combined Cases & $S N C A-140$ & $F_{1,59}=0.064, P=0.802$ \\
& $S N C A-112$ & $F_{1,59}<0.001, P=0.982$ \\
& $S N C A-115$ & $F_{1,59}=0.887, P=0.35$ \\
& \\
\hline Post mortem Interval & \\
\hline Combined Cases & $S N C A-140$ & $F_{1,59}=0.020, P=0.888$ \\
& $S N C A-112$ & $F_{1,59}=0.440, P=0.509$ \\
& $S N C A-115$ & $F_{1,59}=3.432, P=0.07$ \\
\hline Brain Weight & & \\
\hline Combined Cases & $S N C A-140$ & $F_{1,59}=10.475, P=0.002$ \\
& $S N C A-112$ & $F_{1,59}=4.191, P=0.045$ \\
& $S N C A-115$ & $F_{1,59}=10.904, P=0.002$ \\
\hline
\end{tabular}


Table 3. Genotype and allele frequencies for the eight SNCA SNPs and association results.

\begin{tabular}{|c|c|c|c|c|c|c|c|c|c|c|c|c|}
\hline \multirow{3}{*}{$\frac{\text { SNP }}{\text { rs356168 }}$} & \multirow{3}{*}{$\frac{\text { Genotype }}{\text { AA }}$} & \multicolumn{4}{|c|}{ Genotype Freq. N (\%) } & \multirow{3}{*}{$\frac{\chi^{2}(P)}{1.37}$} & \multirow{3}{*}{$\frac{\text { Allele }}{\mathrm{A}}$} & \multicolumn{5}{|c|}{ Allele Freq. N (\%) } \\
\hline & & \multicolumn{2}{|c|}{ Controls } & \multicolumn{2}{|c|}{ Alcohol misusers } & & & \multicolumn{2}{|c|}{ Controls } & \multicolumn{2}{|c|}{ Alcohol misusers } & \multirow{3}{*}{$\begin{array}{c}\chi^{2}(\boldsymbol{P}) \\
1.19 \\
(0.276)\end{array}$} \\
\hline & & 33 & $(26.4)$ & 42 & $(36.5)$ & & & 141 & $(56.4)$ & 141 & $(61.3)$ & \\
\hline & $\mathrm{AG}$ & 75 & $(60.0)$ & 57 & (49.6) & $(0.241)$ & $\mathrm{G}$ & 109 & $(43.6)$ & 89 & $(38.7)$ & \\
\hline & GG & 17 & $(13.6)$ & 16 & (13.9) & & & 250 & & 230 & & \\
\hline & Total & 125 & & 115 & & & & & & & & \\
\hline \multirow[t]{4}{*}{ rs356200 } & AA & 31 & $(25.0)$ & 34 & $(31.0)$ & 0.37 & $\mathrm{~A}$ & 138 & $(55.6)$ & 128 & $(58.2)$ & 0.31 \\
\hline & $\mathrm{AG}$ & 76 & $(61.3)$ & 60 & $(54.5)$ & $(0.540)$ & $\mathrm{G}$ & 110 & $(44.4)$ & 92 & $(41.8)$ & $(0.580)$ \\
\hline & GG & 17 & $(13.7)$ & 16 & $(14.5)$ & & & 248 & & 220 & & \\
\hline & Total & 124 & & 110 & & & & & & & & \\
\hline \multirow[t]{4}{*}{ rs356221 } & AA & 30 & $(24.4)$ & 20 & $(17.4)$ & 5.20 & $\mathrm{~A}$ & 126 & $(51.2)$ & 94 & $(40.9)$ & 5.12 \\
\hline & $\mathrm{AT}$ & 66 & $(53.7)$ & 54 & $(47.0)$ & $(0.023)$ & $\mathrm{T}$ & 120 & (48.8) & 136 & $(59.1)$ & $(0.024)$ \\
\hline & TT & 27 & (21.9) & 41 & $(35.6)$ & & & 246 & & 230 & & \\
\hline & Total & 123 & & 115 & & & & & & & & \\
\hline \multirow[t]{4}{*}{ rs356219 } & AA & 39 & (31.9) & 59 & $(51.8)$ & 9.97 & A & 142 & $(58.2)$ & 164 & (71.9) & 9.75 \\
\hline & $\mathrm{AG}$ & 64 & $(52.5)$ & 46 & (40.3) & $(0.002)$ & $\mathrm{G}$ & 102 & (41.8) & 64 & (28.1) & $(0.002)$ \\
\hline & GG & 19 & (15.6) & 9 & $(7.9)$ & & & 244 & & 228 & & \\
\hline & Total & 122 & 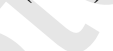 & 114 & & & & & & & & \\
\hline \multirow[t]{4}{*}{ rs7684318 } & $\mathrm{TT}$ & 102 & (83.6) & 86 & $(88.7)$ & 1.14 & $\mathrm{~T}$ & 224 & (91.8) & 183 & $(94.3)$ & 1.05 \\
\hline & $\mathrm{TC}$ & 20 & (16.4) & 11 & (11.3) & $(0.287)$ & $\mathrm{C}$ & 20 & $(8.2)$ & 11 & $(5.7)$ & $(0.306)$ \\
\hline & $\mathrm{CC}$ & 0 & (0) & 0 & (0) & & & 244 & & 194 & & \\
\hline & Total & 122 & & 97 & & & & & & & & \\
\hline \multirow{4}{*}{ rs2736990 } & $\mathrm{TT}$ & 39 & $(31.2)$ & 45 & $(39.5)$ & 1.39 & $\mathrm{~T}$ & 140 & $(56.0)$ & 140 & $(61.4)$ & 1.43 \\
\hline & CT & 62 & (49.6) & 50 & $(43.9)$ & (0.239) & $\mathrm{C}$ & 110 & $(44.0)$ & 88 & (38.6) & $(0.231)$ \\
\hline & $\mathrm{CC}$ & 24 & (19.2) & 19 & $(16.6)$ & & & 250 & & 228 & & \\
\hline & Total & 125 & & 114 & & & & & & & & \\
\hline \multirow[t]{4}{*}{ rs2736995 } & $\mathrm{TT}$ & 58 & $(48.0)$ & 73 & $(64.0)$ & 6.65 & $\mathrm{~T}$ & 166 & (68.6) & 181 & (79.4) & 7.08 \\
\hline & TG & 50 & (41.0) & 35 & $(30.7)$ & $(0.010)$ & $\mathrm{G}$ & 76 & (31.4) & 47 & (20.6) & $(0.008)$ \\
\hline & GG & 13 & $(11.0)$ & 6 & $(5.3)$ & & & 242 & & 228 & & \\
\hline & Total & 121 & & 114 & & & & & & & & \\
\hline \multirow[t]{4}{*}{ rs2301134 } & $\mathrm{TT}$ & 33 & $(26.4)$ & 24 & $(21.1)$ & 0.88 & $\mathrm{~T}$ & 129 & (51.6) & 108 & $(47.4)$ & 0.85 \\
\hline & $\mathrm{CT}$ & 63 & $(50.4)$ & 60 & (52.6) & $(0.348)$ & $\mathrm{C}$ & 121 & $(48.4)$ & 120 & (52.6) & $(0.355)$ \\
\hline & $\mathrm{CC}$ & 29 & $(23.2)$ & 30 & $(26.3)$ & & & 250 & & 228 & & \\
\hline & Total & 125 & & 114 & & & & & & & & \\
\hline
\end{tabular}


Table 4: Association analysis of haplotypes formed by the SNPs: rs356221 and rs356219.

\begin{tabular}{lllll}
\hline Haplotype & $\begin{array}{l}\text { Controls } \\
\text { frequency }\end{array}$ & $\begin{array}{l}\text { Alcohol } \\
\text { misusers } \\
\text { frequency }\end{array}$ & Permutated $\chi^{2}$ & Permutated $\boldsymbol{P}$ \\
\hline AT & 0.472 & 0.590 & 6.678 & $\mathbf{0 . 0 2 6 5}$ \\
GA & 0.406 & 0.284 & 7.839 & $\mathbf{0 . 0 1 4 3}$ \\
AA & 0.104 & 0.125 & 0.496 & 0.9380 \\
\hline $\begin{array}{l}* \\
\text { testing bias. }\end{array}$ & & & \\
$*$ The frequency of the TG haplotype was less than $1 \%$ and therefore excluded from analysis. \\
Bold type indicates $P<0.05$.
\end{tabular}


Table 5. Influence of SNCA 3'UTR haplotypes on $\alpha$-synuclein expression.

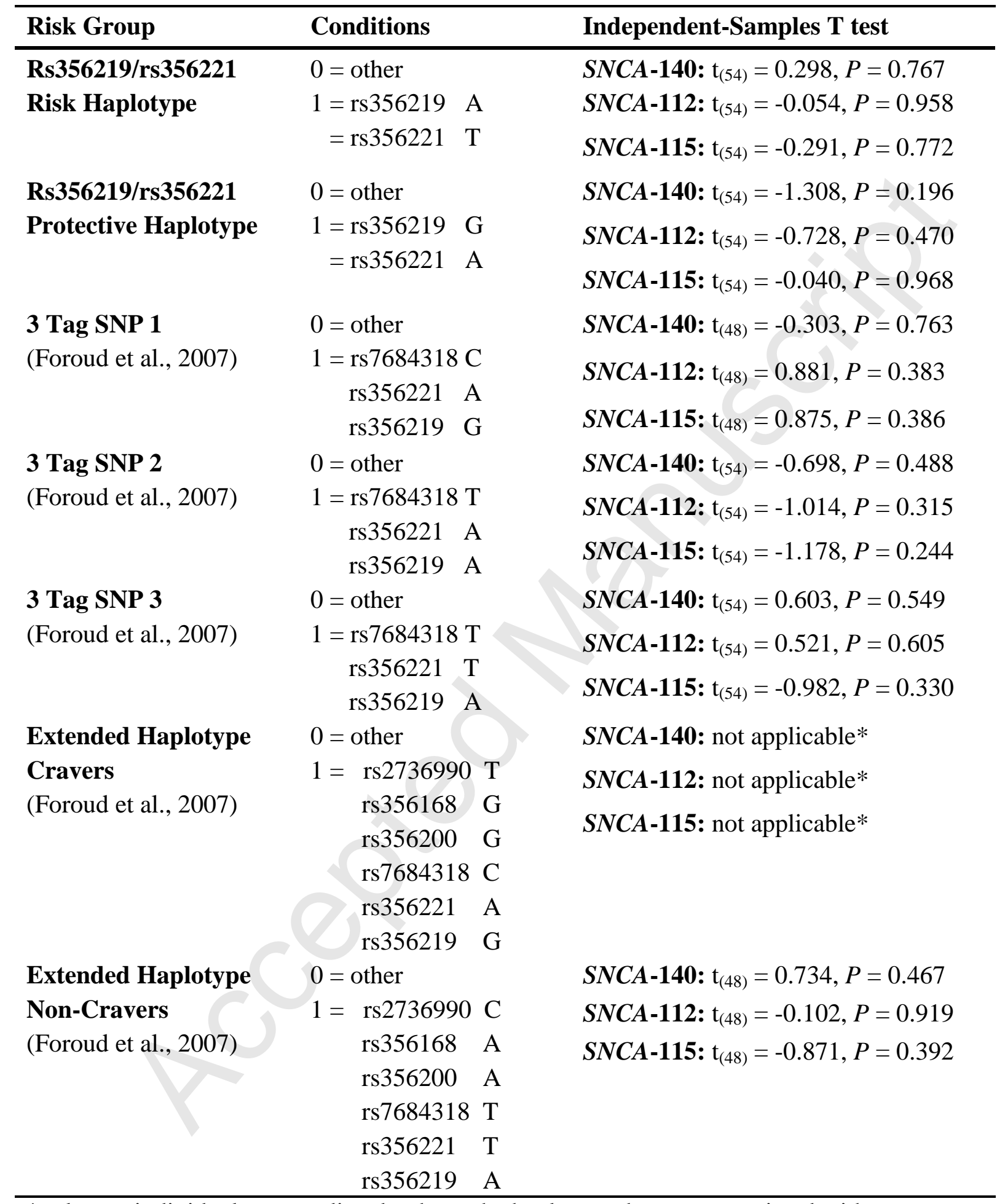

*only one individual was predicted to have the haplotype that was associated with cravers (Foroud et al., 2007). 


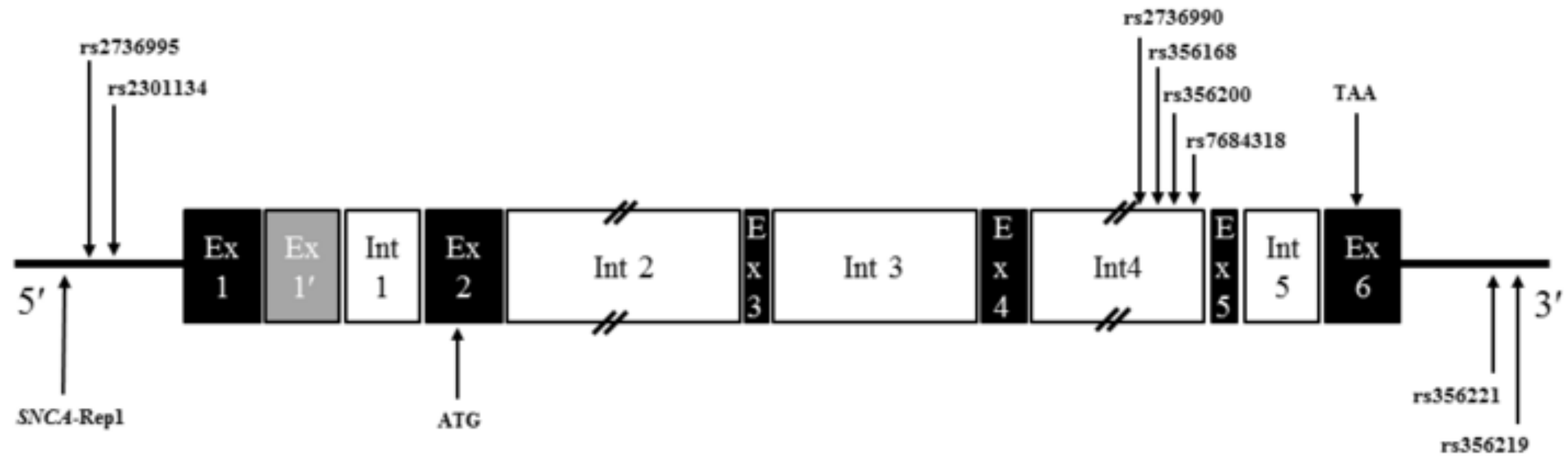


Figure
Click here to download high resolution image

Roverve Exgression of a-Symaciein Variant 140

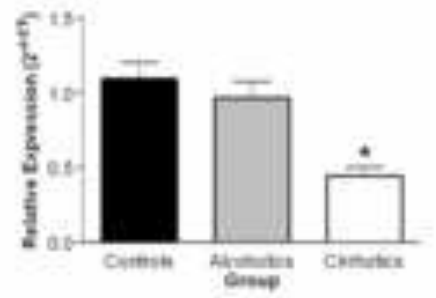

Folatine Expression of a-5 ymeinin Variant 112

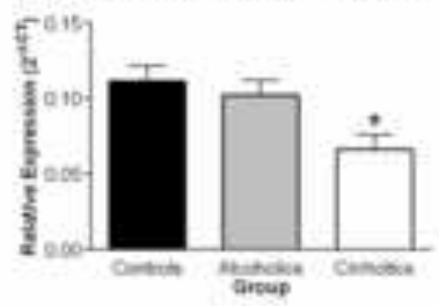

Retaeve Ergatsolon ce is-Symuciein Vartart 115

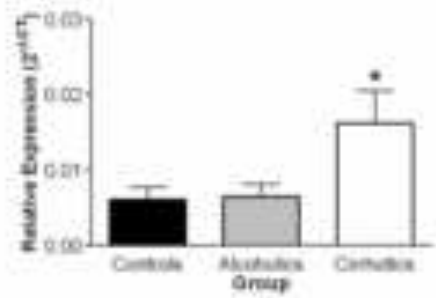



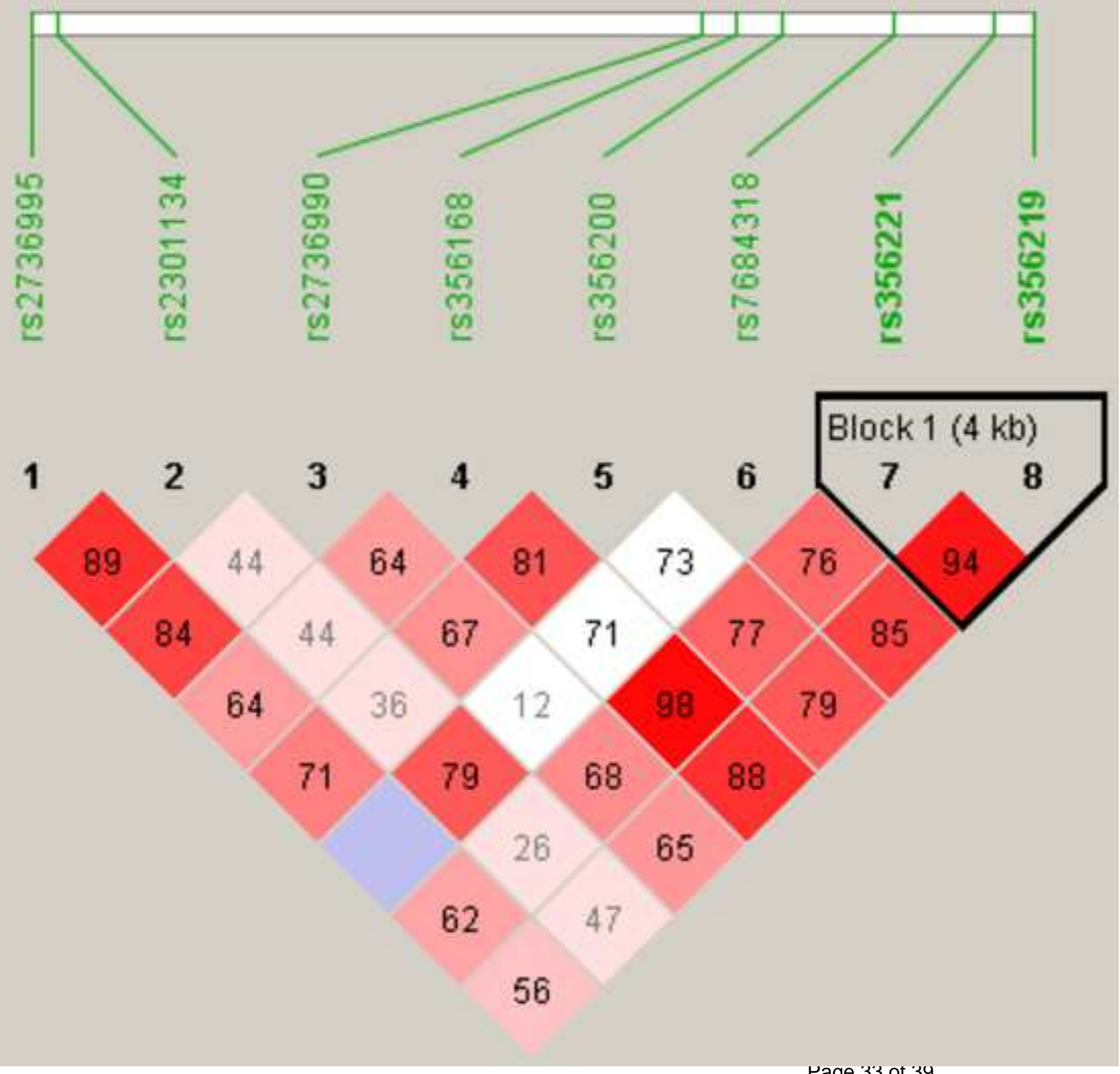
Supplementary Material
Click here to download S

i $\mathrm{C}$ C $=\mathrm{n}$

Click here to download Supplementary Material: ADED140052_smcover.docx

Page 34 of 39 


\section{Contributors}

PD and JL were responsible for the study concept and design. CB acquired the expression data. PJ, PD and JL assisted with data analysis and interpretation of findings. PJ, CB and JL drafted the manuscript. PD provided critical revision of the manuscript for important intellectual content. All authors critically reviewed content and approved final version for publication. 
Conflict of Interest
No conflict declared

Conflict of Interest
No conflict declared

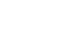




\section{Role of Funding Source}

Nothing declared

\section{Contributors}

PD and JL were responsible for the study concept and design. CB acquired the expression data. PJ, PD and JL assisted with data analysis and interpretation of findings. PJ, CB and JL drafted the manuscript. PD provided critical revision of the manuscript for important intellectual content. All authors critically reviewed content and approved final version for publication.

\section{Conflict of Interest}

No conflict declared

\section{Acknowledgements}

We would like to acknowledge the Australian Brain Bank Network, who supplied the brain tissue for analysis. Allison Eckert and Donna Sheedy provided detailed information on the cases. We thank the next of kin for providing informed consent for the studies. Funding for the project was supplied by Molecular Basis of Disease Program, Menzies Health Institute Queensland, Griffith University. 


\section{Highlights:}

- The expression of $S N C A-140$ and $S N C A-112$ was significantly lower in cirrhotic alcohol misusers than in controls

- The expression of SNCA-115 was significantly greater in cirrhotic alcohol misusers than in controls

- The allele and genotype frequencies for three SNPs (rs356221, rs356219 and rs2736995) differed significantly between alcohol misusers and controls

- Two SNPs, rs356221 and rs356219, were in high linkage disequilibrium

- There was no increased risk of alcoholism associated with specific genotypes or haplotypes in our population

- Results suggest that the rs356219/356221 G-A haplotype may decrease the chance of having an alcohol misuse phenotype

- Sequence variation in the 3'-UTR of the gene did not affect the expression of $\alpha$ synuclein splice variants

- SNPs were not significantly associated with $\alpha$-synuclein gene expression in our population 


\section{Accepted Manuscript}

Title: Differential Expression of $\alpha$-Synuclein Splice Variants in the Brain of Alcohol Misusers: Influence of Genotype

Author: Paulina Janeczek Corinne Brooker Peter Dodd Joanne M. Lewohl

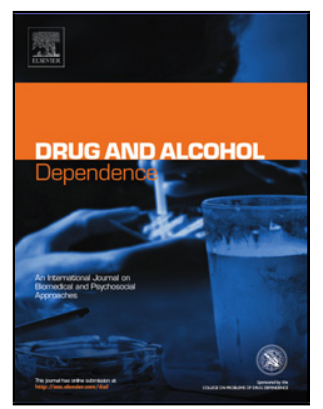

PII: S0376-8716(15)00304-X

DOI: http://dx.doi.org/doi:10.1016/j.drugalcdep.2015.05.045

Reference: DAD 5625

To appear in:

\section{Drug and Alcohol Dependence}

Received date: 4-12-2014

Revised date: 28-5-2015

Accepted date: 28-5-2015

Please cite this article as: Janeczek, P., Brooker, C., Lewohl, P.D.,J.M., Differential Expression of rmalpha-Synuclein Splice Variants in the Brain of Alcohol Misusers: Influence of Genotype, Drug and Alcohol Dependence (2015), http://dx.doi.org/10.1016/j.drugalcdep.2015.05.045

This is a PDF file of an unedited manuscript that has been accepted for publication. As a service to our customers we are providing this early version of the manuscript. The manuscript will undergo copyediting, typesetting, and review of the resulting proof before it is published in its final form. Please note that during the production process errors may be discovered which could affect the content, and all legal disclaimers that apply to the journal pertain. 